\title{
Symptoms-Based Evaluation of Iron Deficiency Anemia in Students of Bahawalpur Correlated with their Eating Habits
}

\author{
Haji Muhammad Shoaib Khan ${ }^{1}$, Muhammad Sohail ${ }^{1}$, Atif Ali ${ }^{1,3 *}$, Naveed Akhtar ${ }^{1}$, \\ Hira Khan ${ }^{1}$ and Fatima Rasool ${ }^{2}$ \\ ${ }^{1}$ Department of Pharmacy, Faculty of Pharmacy and Alternative Medicine, The Islamia University of Bahawalpur, Bahawalpur- \\ Pakistan; ${ }^{2}$ University College of Pharmacy, University of Punjab, Lahore- Pakistan; ${ }^{3}$ Institute of Pharmaceutical Sciences, \\ University of Veterinary and Animal Sciences, Lahore- Pakistan
}

*For correspondence: Email: ajmaline2000@gmail.com

\begin{abstract}
Purpose: To conduct a symptoms-based evaluation of iron deficiency anemia (IDA) in university and colleges students of Bahawalpur- Pakistan and correlate the data with their eating habits.

Methods: A cross-sectional survey was accomplished using a questionnaire for the assessment of IDA among 500 students enrolled in the Islamia University of Bahawalpur and two affiliated colleges in Bahawalpur, Pakistan. Symptoms-based evaluation was carried out to obtain the results.

Results: The results showed that $41.2 \%$ (206 students) of the 500 students were anemic. The proportion of anemic females and males was $65.53 \%$ (135) and $34.46 \%$ (71), respectively. Of the 206 students, $96.11 \%$ (198) were below the age of 25 years, $83.96 \%$ (173) in official hostels, $52.42 \%$ (108) belonged to families of average socioeconomic status, $77.18 \%$ (159) suffer from short-term memory, and $47.08 \%$ (97) were unaware of IDA. The most commonly observed symptoms were flattened brittle nails, dizziness, and fatigue after physical activity, $88.83 \%$ (183); presence or absence of glosittis $87.37 \%$ (180); ringing in the ears, $84.46 \%$ (174); headache, $62.62 \%$ (129); frequent minor infections, $46.60 \%$ (96); shortness of breath, $40.29 \%$ (83); taste disturbance, $35.92 \%$ (74); ice cravings, $22.33 \%$ (46); and angular stomatitis $18.97 \%$ (39).

Conclusion: An unexpectedly large number of female students exhibit symptoms of IDA due to poor nourishment. Findings from this survey can be used in awareness programs to increase academic performance in young adults and to eliminate IDA.
\end{abstract}

Keywords: Iron deficiency Anemia, Students, Eating habits, Awareness programs

Tropical Journal of Pharmaceutical Research is indexed by Science Citation Index (SciSearch), Scopus, International Pharmaceutical Abstract, Chemical Abstracts, Embase, Index Copernicus, EBSCO, African Index Medicus, JournalSeek, Journal Citation Reports/Science Edition, Directory of Open Access Journals (DOAJ), African Journal Online, Bioline International, Open-J-Gate and Pharmacy Abstracts

\section{INTRODUCTION}

Iron is a crucial micronutrient required for oxygen transport, oxidative metabolism, cellular proliferation and physiological processes [1]. Iron absorption is up-regulated by iron deficiency and increased erythropoiesis. It is down regulated in inflammation resulting iron repletion. It is mediated by the regulator of iron homeostasis that blocks iron release from enterocytes and macrophages which results in anemia [2].
The World Health Organization (WHO) defines anemia as hemoglobin level below $130 \mathrm{~g} / \mathrm{L}$ in men, $120 \mathrm{~g} / \mathrm{L}$ in women and $110 \mathrm{~g} / \mathrm{L}$ in pregnant women $[3,4]$. Iron deficiency can delay normal infant motor function during pregnancy, increase the risk for small or early (pre-term) babies, cause fatigue in adults and affect memory or other mental functions in teens [5]. Helicobacter pylori colonization is also bracketed with IDA which may spoil iron uptake/intensify iron loss 
[6]. Pregnancy fallouts in an overall surplus iron constraint is about $1000 \mathrm{mg}$ [7]. IDA is one of the extensive causes of poor academic performance and low level of health status of students [9]. The common signs of developing anemia are chronic fatigue, loss of appetite, headaches, irritability and loss of concentration. IDA causes minor health dilemmas that may lead to complicated diseases. Students in educational institutes should be made aware of this health issue so that they can take steps to improve both curricular and extracurricular performances. IDA is associated with impaired cognitive development in pre-school-aged children and diminished work productivity in adults [8].

The purpose of this study was to conduct a symptoms-based evaluation of IDA in university and college students of Bahawalpur- Pakistan and correlate the data with their eating habits.

\section{METHODS}

Evidence-based study was accomplished to evaluate awareness about the prevalence of different IDA symptoms in the students in Bahawalpur, Pakistan. To accomplish the study, a questionnaire was designed. Questionnaires were circulated by a five-membered team of students to 500 students in the Islamia University of Bahawalpur, affiliated colleges (SE college and Degree College Bahawalpur) and various hostels of the city. Students belonging to different regions, different age groups, different races and different socio-economic status filled questionnaires.

The filled questionnaires contained the demographic data of the students and 14 major symptoms of IDA commonly found and observed in anemic patients. The questionnaire also contained a table containing the routine nutritional habits of the students. Non-specific data of 500 students was collected and evaluated for presence of symptoms and their eating habits to find out the prevalence of anemia that they mentioned in questionnaires. The students showing symptoms of anemia according to set criteria were separated [9]. The most common signs of anemia were taken to be chronic fatigue, loss of appetite, headaches, irritability, loss of concentration, brittle nails, angular stomatitis, ice cravings, paleness of skin and eyes, shortness of breath, headache and taste disturbance etc. Those students who showed 5 or more IDA symptoms were considered anemic [10].

\section{Statistical analysis}

Statistical Package for Social Sciences 17.0 software was used to analyze the data in mean and percentage by using computer to find out symptoms-based evaluation of IDA in these students.

\section{RESULTS}

Of the 500 students, $41.2 \%$ (206) were anemic while $58.8 \% \quad(294)$ were non-anemic. Furthermore, out of 206 that were anemic, the proportion of anemic females was greater than that of males (Table 1). A large number of students $(96.11 \%)$ were below the age of 25 years.

Table 1: Age and sex wise distribution of anemic students $(n=206)$

\begin{tabular}{lll}
\hline Age & $>25$ years & $3.88 \%(8)$ \\
& $<25$ years & $96.11 \%(198)$ \\
Sex & Male & $34.46 \%(71)$ \\
& Female & $65.53 \%(135)$ \\
\hline
\end{tabular}

As the study was based on the evaluation of students, who are usually of two categories; either hostel boarders or those who reside in their homes. Out of 206 anemic students, the results obtained were given in Table 2 in comprehensive manner.

\section{DISCUSSION}

IDA is a nutritional disorder in our community specifically in women and young [11]. In this study, $65.53 \%$ (135) of students were females and most of the cases were the age group below 25 years. IDA was found to be more common among females than males. That is due to the probability of iron deficiency that upsurges at puberty, menstruation and iron constraints [12]. A hefty number of students narrated that they were having few health problems that were outstandingly associated to IDA. Unfortunately, many of them were not aware that they suffered. Boarder students were found to be more anemic than non-boarder. They do not annex adequate diet, yet work hard as laborers and as a result fosters a number of nutritional flaws as well as iron deficiency. Inferior hygiene brews them susceptible to parasitic infestations, particularly hookworm infection [13]. The $3^{\text {rd }}$ National Health and Nutrition Examination Survey conducted during 1988 to 1994 in USA which exposed that the occurrence of iron deficiency is higher among children living at or below the poverty level than those living above the poverty level [14]. As most of the students were boarder and belonged to 
Table 2: Evaluation of social profile of 206 anemic students

\begin{tabular}{lll}
\hline Social profile & Aspect & $\% \mathbf{~ ( N )}$ \\
\hline Residence & Hostel resident & $83.98 \%(173)$ \\
Socioeconomic status & Non-hostel resident & $16.01 \%(33)$ \\
& Rich & $36.89 \%(76)$ \\
& Average & $52.42 \%(108)$ \\
Academic status & Poor & $10.67 \%(22)$ \\
& Average & $65.53 \%(135)$ \\
Memory status & Above Average & $34.46 \%(71)$ \\
Self-analysis & Long- term & $22.81 \%(47)$ \\
& Short- term & $77.18 \%(159)$ \\
Eating habits (per day) & Aware & $52.91 \%(109)$ \\
& Unaware & $47.08 \%(97)$ \\
& Take Grains & $77.66 \%(160)$ \\
& Fruit & $13.10 \%(27)$ \\
Symptoms variations & Milk & $48.54 \%(100)$ \\
& Vegetables & $55.82 \%(115)$ \\
& Meat & $43.68 \%(90)$ \\
& Dizziness and fatigue after physical activity & $88.83 \%(183)$ \\
& Pale nails & $19.41 \%(40)$ \\
& Frequent minor infections & $46.60 \%(96)$ \\
& Shortness of breath & $40.29 \%(83)$ \\
& Taste disturbance & $35.92 \%(74)$ \\
& Headache & $62.62 \%(129)$ \\
& Ice craving & $22.33 \%(46)$ \\
& Flattened brittle nails & $88.83 \%(183)$ \\
& Angular stomatitis & $18.933 \%(39)$ \\
& Glosittis & $87.37 \%(180)$ \\
& Ringing in the ears & $84.46 \%(174)$ \\
\hline
\end{tabular}

average family so their nutritional inadequacy was found to be the second most general cause of IDA. These patients did not have any associated disease. The students taking milk, meat, grains and cereals were having comparatively low iron deficiency. Common symptoms were the headaches, dizziness, glosittis, fatigue after physical activity, frequent minor infections brittle nails and ice cravings. Short- term memory status was the problem of $77.18 \%$ (159) of students but academic performance was not that much affected according to their opinion. Poor socio-economic status was the salient problem behind IDA in majority of cases. The students enjoying the status of boarder were having more \% age of anemia than those living in their homes. Food habits were having clear evidences on anemia.

Among copious dynamics of anemia, nutritional aspects like vitamins and iron contribute to the onset of anemia, foremost to iron deficiency. IDA is frequently cured by taking iron rich diet \& iron supplements regularly. But it is still common and undercover disease prevailing in our community. The incidence and prevalence of IDA can also be reduced by iron fortification of various foodstuffs under the supervision of health department of government [15].

\section{Limitations of the study}

The study was cross-sectional and therefore, the directionality of the associations could not be determined.

\section{CONCLUSION}

Female students living in boarding accommodation shower more symptoms of IDA due to inadequate nourishment as they particularly experienced dizziness and fatigue after physical activity, thus affecting their work performance considerably. Awareness programs should be conducted to promote awareness and improve performance in young adults and eliminate IDA.

\section{REFERENCES}

1. Grantham-McGregor S, Ani C. A review of studies on the effect of iron deficiency on cognitive development in children. J Nutr. 2001; 131: 649S-666S.

2. Nair KM, Lyengar M. Iron content, bioavailability \& factors affecting iron status of Indians. Indian $J$ Med Res.2009; 130: 634-645.

3. Sant-Rayn SP, Stephen CFB, Katrina JA, Peter RG, Lawrence $P M$, John KO, Simon DR, Helen FS, Ramdas T, Amanda RT, Erica MW, Kathryn LR. Diagnosis and management of iron deficiency anaemia: a clinical update. Med J Aust. 2010; 193 (9): 525-532 
4. Wiveka EE. Why should women have lower reference limits for haemoglobin and ferritin concentrations than men? Brit Med J. 2001; 322: 1355-1357.

5. Christopher VC, Alastair JSS, Cate ED. Anemia in Cambodia: prevalence, etiology and research needs. Asia Pac J Clin Nutr. 2012; 21(2):171-181.

6. Kattalin A, Carlos V, Fernando B, Pilar H, Santiago GL. Optimal management of iron deficiency anemia due to poor dietary intake. Inter J Gen Med. 2011; 4: 741-750.

7. Bothwell TH. Iron requirements in pregnancy and strategies to meet them. Am J Clin Nutr. 2000; 72: 257S-264S.

8. Ganz T. Hepcidin- a regulator of intestinal iron absorption and iron recycling by macrophages. Best Pract Res Clin Haematol. 2005; 18: 171-182.

9. Sachdev $H$, Gera $T$, Nestel $P$. Effect of iron supplementation on mental and motor development in children: systematic review of randomized controlled trials. Public Health Nutr. 2005; 8: 117 132.

10. Murray-Kolb LE, Beard JL. Iron treatment normalizes cognitive functioning in young women. Am J Clin Nutr. 2007; 85: 778-787.
11. Muhammad TK, Tasleem A, Mussarat N. Prevalence of anemia among university of Peshawar students. J Postgrad Med Inst. 2010; 24: 265-269.

12._Irshad G, Kousar S, Jafri SA, Ali I. Iron deficiency anemia significance of serum ferritin in diagnosis in pregnant females of Pakistan. Prof. Med. J. 2011; 18: 475-478.

13. Khan SP, Rizwanullah K, Khan AJ, Aziz F. Prevalence of intestinal parasites in children and its effect on hemoglobin level. Pak. J. Med. Res. 1987; 26: 151154.

14. Carolyn CT, Amaya LB, Ruth VM, Ng'ethe M, Peter LM, Eric MM, Uriel $K$, Charles HK, Francis MM. Evaluation of the Health-related Quality of Life of Children in Schistosoma haematobium-endemic Communities in Kenya: A Cross-sectional Study. PLOS Neglect Trop D. 2013; 7: 1-13.

15. Sharma SK, Chaliha L, Mahanta B. Prevalence of anemia and role of $\beta^{E}$-globin gene as an associating factor among college students of Assam: A preliminary report Indian J Comm Med. 2013; 38(1): 53-55. 